\title{
Second Line of Defense Spares Program
}

\author{
DL Henderson \\ AE Holmes \\ G Muller \\ RT Brigantic \\ CJ Perkins \\ SK Cooley \\ TM Mercier \\ DE Thorsen
}

November 2012

Pacific Northwest

NATIONAL LABORATORY

Proudly Operated by Battelle Since 1965 


\title{
DISCLAIMER
}

This report was prepared as an account of work sponsored by an agency of the United States Government. Neither the United States Government nor any agency thereof, nor Battelle Memorial Institute, nor any of their employees, makes any warranty, express or implied, or assumes any legal liability or responsibility for the accu racy, completeness, or usefulness of any information, apparatus, product, or process disclosed, or represents that its use would not infringe privately owned rights. Reference herein to any specific commercial product, process, or service by trade name, trademark, manufacturer, or otherwise does not necessarily constitute or imply its endorsement, recommendation, or favoring by the United States Government or any agency thereof, or Battelle Memorial Institute. The views and opinions of authors expressed herein do not necessarily state or reflect those of the United States Government or any agency thereof.

\section{PACIFIC NORTHWEST NATIONAL LABORATORY \\ operated by \\ BATTELLE \\ for the \\ UNITED STATES DEPARTMENT OF ENERGY \\ under Contract DE-AC05-76RL01830}

Printed in the United States of America

$$
\begin{aligned}
& \text { Available to DOE and DOE contractors from the } \\
& \text { Office of Scientific and Technical Information, } \\
& \text { P.O. Box 62, Oak Ridge, TN } 37831-0062 ; \\
& \text { ph: }(865) 576-8401 \\
& \text { fax: }(865) 576-5728 \\
& \text { email: reports@adonis.osti.gov }
\end{aligned}
$$

\author{
Available to the public from the National Technical Information Service \\ 5301 Shawnee Rd., Alexandria, VA 22312 \\ ph: (800) 553-NTIS (6847) \\ email: orders@ntis.gov <http://www.ntis.gov/about/form.aspx> \\ Online ordering: http://www.ntis.gov
}




\title{
Second Line of Defense Spares Program
}

\author{
DL Henderson \\ RT Brigantic \\ AE Holmes \\ CJ Perkins \\ G Muller \\ TM Mercier \\ SK Cooley \\ DE Thorsen
}

November 2012

Prepared for

the U.S. Department of Energy

under Contract DE-AC05-76RL01830

Pacific Northwest National Laboratory

Richland, Washington 99352 



\section{Summary}

During fiscal year 2012, a team from the Pacific Northwest National Laboratory conducted an assessment and analysis of the Second Line of Defense (SLD) Sustainability spare parts program. Spare parts management touches many aspects of the SLD Sustainability program including contracting and integration of local maintenance providers, equipment vendors, analyses and metrics on program performance, system state of health, and maintenance practices. Standardized spares management will provide better data for decisions during the site transition phase and facilitate transition to partner country sustainability ownership. The effort was coordinated with related Sustainability program initiatives, including a configuration items baselining initiative, a metrics initiative, and a maintenance initiative.

The spares study has also led to pilot programs for sourcing alternatives that include regional intermediate inventories and partnering agreements that leverage existing supply chains. Many partners from the Sustainability program contributed to and were consulted in the course of the study. This document provides a description of the findings, recommendations, and implemented solutions that have resulted from the study. The recommendations are organized in broad categories.

Spares data management. Concerned with how information about spares is gathered, maintained, and made available to support decisions and business processes throughout the program. This work included development of a comprehensive SLD Spare Parts Database and Catalog built from various information sources.

Integration of spares data with site configuration management. A way forward using unambiguous spare parts designations and authoritative information about site configurations to make better programlevel decisions about spares inventory levels, sourcing, shortfalls, and upgrade, refresh, or retrofit.

Spares inventory management. Clear designation of parts for better program-wide visibility and analysis of inventories.

Spares supporting processes. Better spares data to permit functions such as demand-supported inventory management, failure or risk-aware cost projections, and statistical failure analysis.

At closeout of the spares study, the spares database is being transitioned to the control of the Help Desk Portal for database configuration management and integration with Portal functions. The derived spares catalog views are being shared with the SLD Sustainability community to validate design decisions; cleanup erroneous, uncertain, duplicate, or missing data elements; and elicit use cases and requirements that can be implemented in future work or enable ongoing and future initiatives. 



\section{Acronyms and Abbreviations}

$\begin{array}{ll}\text { DOE } & \text { Department of Energy } \\ \text { LMP } & \text { local maintenance provider } \\ \text { MPC } & \text { Master Parts Catalog } \\ \text { MPDB } & \text { Master Parts Database } \\ \text { NNSA } & \text { National Nuclear Security Administration } \\ \text { PNNL } & \text { Pacific Northwest National Laboratory } \\ \text { RSL } & \text { recommended stockage level } \\ \text { SLD } & \text { Second Line of Defense }\end{array}$





\section{Contents}

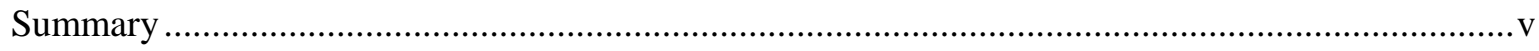

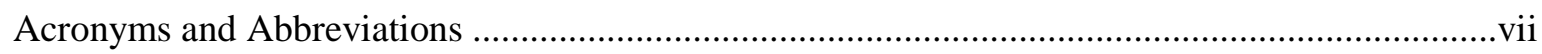

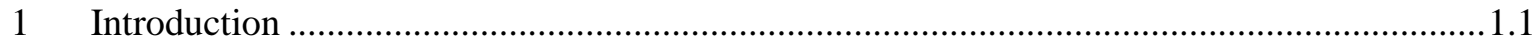

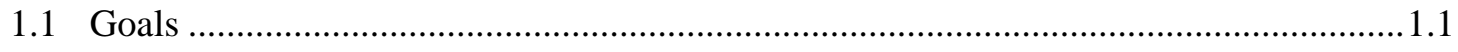

1.1.1 Identify, Collect, Collate, and Organize Spares Data........................................1.1

1.1.2 Identify and Recommend Process Improvements for Spares Management ..........1.2

1.1.3 Integrate Spares Management with Program Initiatives .....................................1.2

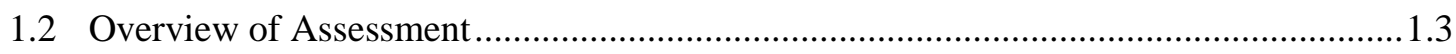

1.2.1 Information and Data Management.....................................................................

1.2.2 Resource Management and Material Handling .................................................1.4

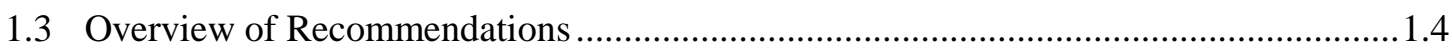

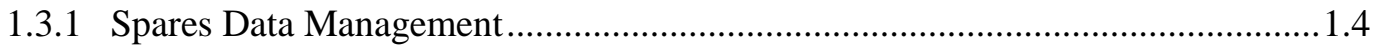

1.3.2 Integration of Spares Data with Site Configuration Management .......................1.5

1.3.3 Spares Inventory Management.....................................................................

1.3.4 SLD Spares Support Processes.......................................................................... 1.5

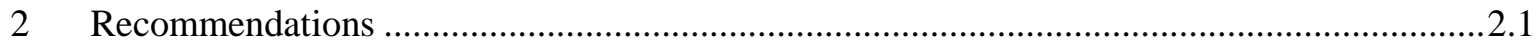

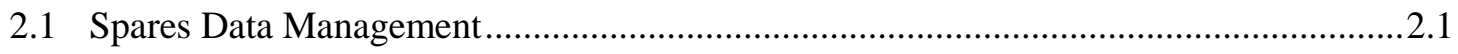

2.2 Integration with Configuration Management Task Force ..............................................2.2

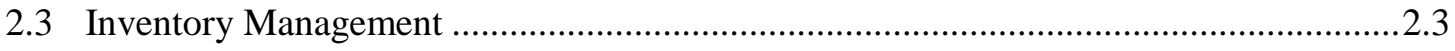

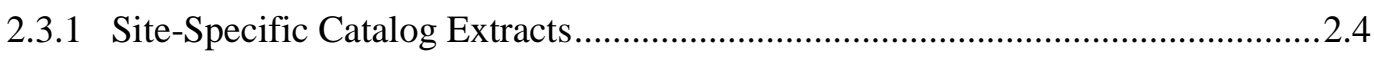

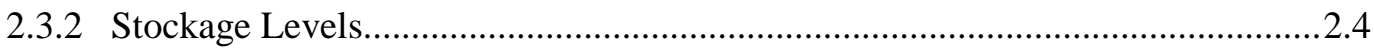

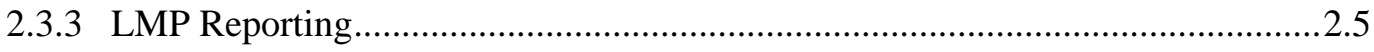

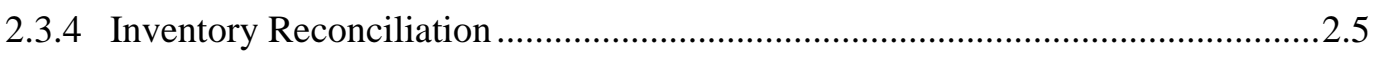

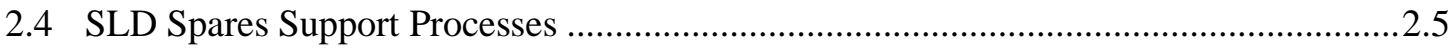

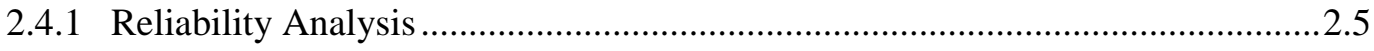

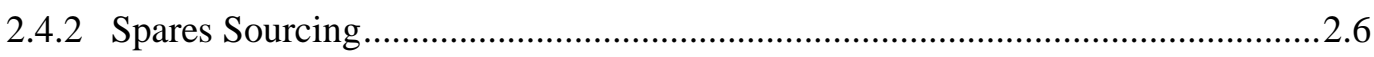

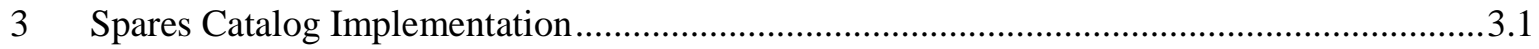

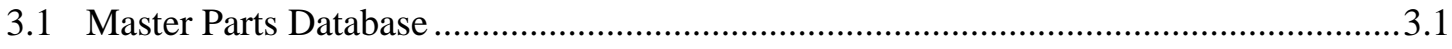

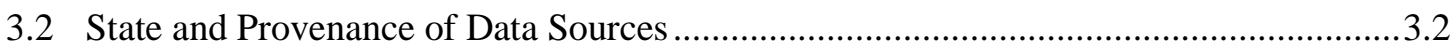

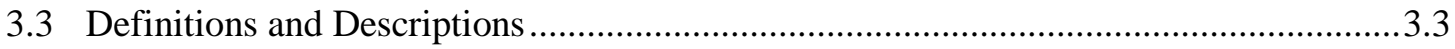

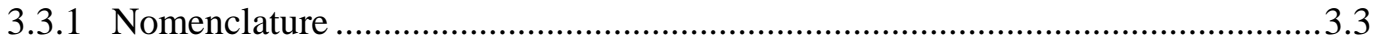

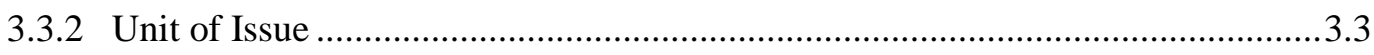

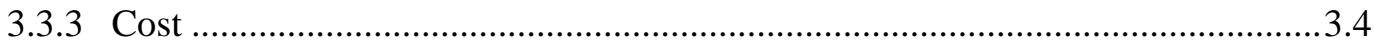

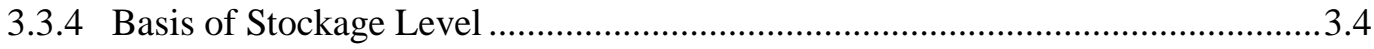

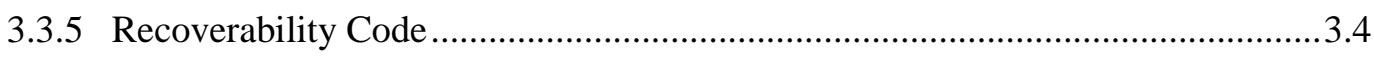

3.3.6 Special Handling Code........................................................................................ 3.5 


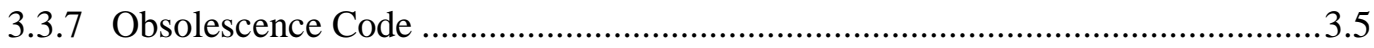

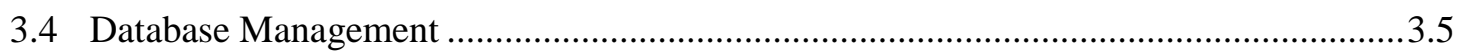

3.4.1 Update and Ingestion Process............................................................................. 3.5

3.4.2 Structure, Relationships, and Modification Process................................................ 3.6

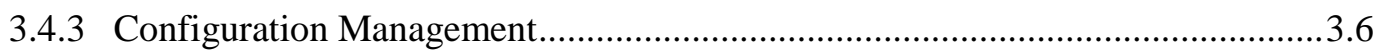

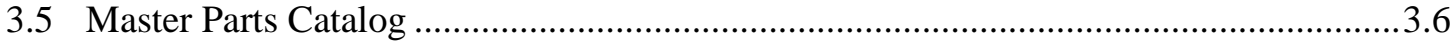

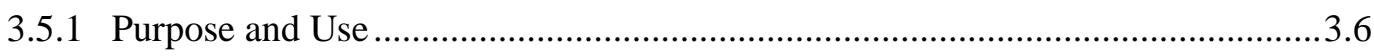

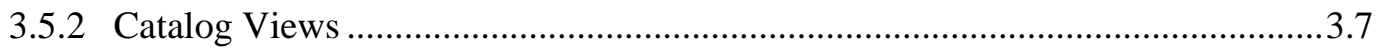

$4 \quad$ Recommendations for Near-Term Implementation........................................................... 4.1

4.1 Integrate Master Parts Database with Portal ................................................................. 4.1

4.2 Integrate MPC with Site Configurable Items Database ............................................... 4.1

4.3 Data-Driven Reliability Analysis ............................................................................... 4.1

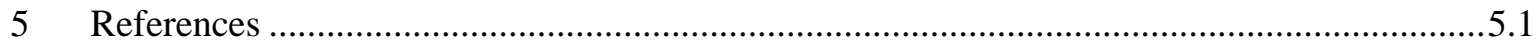




\section{Figures and Tables}

\section{Figures}

Figure 2.1. Example Configuration Baseline Data ..................................................................2.2

Figure 2.2. Catalog and Inventory Process Relationships.......................................................2.3

Figure 3.1. MPDB Relational Table Diagram ......................................................................... 3.1

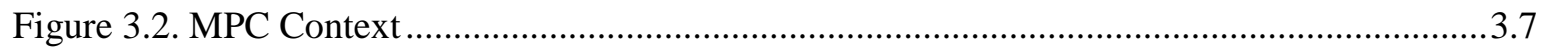

\section{Tables}

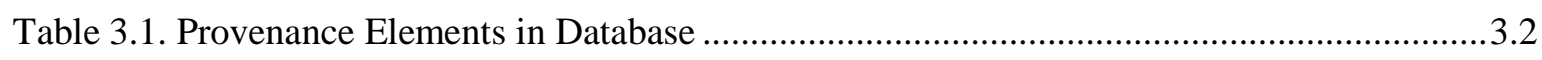

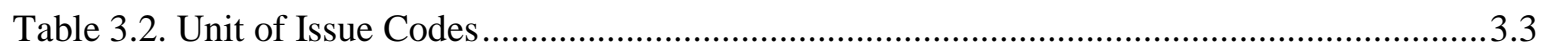

Table 3.3. Basis of Stockage Level Codes ....................................................................................

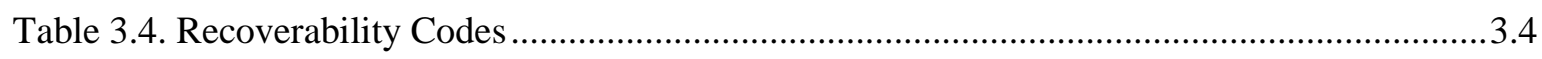

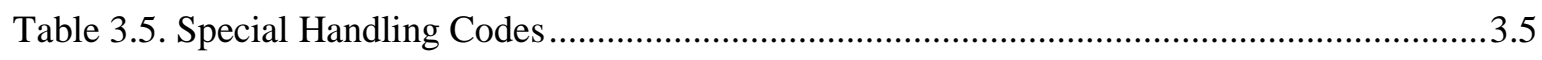

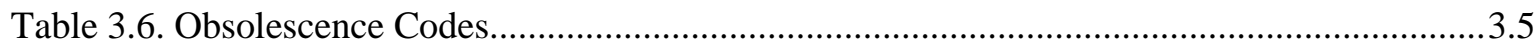





\section{Introduction}

This document describes the findings, recommendations, and implemented solutions that have resulted from a study of Second Line of Defense (SLD) Sustainability program spare parts. The SLD Program is part of the Department of Energy's (DOE's) National Nuclear Security Administration (NNSA). The program accomplishes its critical global security mission by forming cooperative relationships with partner countries to install passive radiation detection systems that augment traditional inspection and law enforcement measures by alerting border officials to the presence of special nuclear or other radiological materials in cross-border traffic. An important tenet of the program is to work collaboratively with these countries to establish the necessary processes, procedures, infrastructures, and conditions that will enable them to fully assume the financial and technical responsibilities for operating the equipment.

The equipment is required to operate continuously, often at remote locations with limited infrastructure. In order to provide required operational availability, there must be a maintenance competency and inventory of spare parts and consumables. The SLD Program faces an increasingly complex logistics process as it moves from a deployment focus to a transition and sustainability focus. A critical requirement of transition is to assure timely and efficient supply of spare parts.

The Pacific Northwest National Laboratory (PNNL) has been designated by DOE-SLD to work closely with partner countries to jointly develop sustainability plans that are designed to ensure installed radiation detection systems remain effective not only throughout the sustainability period but also once partner countries assume full responsibility for the performance of the systems.

In support of these goals, PNNL has undertaken a holistic study of the existing SLD spares system with the goal of providing both an assessment of the current processes and concrete recommendations for program improvement based on thorough analysis. This analysis was performed by a team comprising expertise in systems engineering, operations research, supply chain management, maintenance logistics, data analysis, and statistics.

\subsection{Goals}

As part of an initial assessment, the spares study team developed a set of recommendations with the following study goals:

\subsubsection{Identify, Collect, Collate, and Organize Spares Data}

Where possible, classify parts appropriately for use in level of repair analysis, economic life, hazardous material, and similar spares management considerations. The collection of this information in a standardized format supports decision making across the program. These management decisions include: inventory collection and management across the deployed fleet, spares reconciliation processes, spares trending and failure analysis, procurement decisions, and lifecycle management. The recommended solutions support various functions: recovery, replacement and refurbishment, technology refresh, and improved planning capabilities for SLD and partner countries to support the long-term viability of the program. 


\subsubsection{Identify and Recommend Process Improvements for Spares Management}

To enable transition, assist local maintenance providers (LMPs) and country, sustainability, and program managers with transition and interim program activities. Improve integration with the LMP inventory process to reconcile a set of inventories to manage shortage or excess spares.

Develop a Master Parts Catalog (MPC) to enable transition of SLD radiation detection systems to partner countries by defining the set of equipment and materials necessary for the operation and maintenance of these systems. The MPC provides data about disposition, sourcing, obsolescence, and a means to crossreference interchangeable replacement parts.

Develop a Master Parts Database (MPDB) to enable inventory management that provides a means to assess needs for spares across the program, reconcile inventory imbalances, and understand consumption and wear cycles for system components. Spares consumption informs budgeting and lifecycle planning for deployed systems, including acquisition of spares. Consumption and wear cycles inform technology maturation, future deployment considerations (e.g., component hardening), and lifecycle planning for technology refreshment and component replacement. An understanding of the costs associated with these needs informs the decision to extend the service life of existing equipment, pursue research and development for new technology, and acquire new systems to replace equipment nearing end of life.

\subsubsection{Integrate Spares Management with Program Initiatives}

The SLD Sustainability approach to spares management should be integrated with other program initiatives that provide key underpinnings for the spares program.

\subsubsection{Metrics Working Group}

The Metrics Working Group is tasked with constructing a set of clearly defined sustainability metrics. These metrics serve a critical purpose in providing decision makers with an understanding of how well the SLD systems perform the specified mission. They also enable clear communication about the achievement of program goals and gaps in program resourcing. An SLD spares program serves a supporting role for the overall program objectives captured in these metrics and supports the program in improving overall performance according to these metrics.

\subsubsection{Maintenance Task Force}

The Maintenance Working Group is tasked with developing maintenance packages focused on the radiation detection subsystems, including development of functional descriptions and functional failure definitions. These products will be used to develop a set of maintenance work packages that the LMP will be expected to follow. The spares program supports this effort by enabling unambiguous attribution of malfunctions and corrective actions to relevant parts.

\subsubsection{Configuration Items Working Group}

The Configuration Items Working Group is tasked with creating clearly defined and categorized configuration baselines to enable more consistent tracking, reporting, and management across the Sustainability program. The MPDB will conform to the data standards of the configuration baseline and provide a centralized, unambiguous collection of data about those parts that are also under configuration management. 


\subsubsection{Inform Overall SLD Sustainability Program Development}

The spares program supports a clearer understanding of the operations and maintenance costs for deployed radiation detection systems. It informs decisions about logistics management, service life extension, research and development, and acquisition. These decisions impact the capability of partner countries to assume, operate, and sustain SLD radiation detection systems.

\subsection{Overview of Assessment}

The SLD Sustainability program is a continuously evolving combination of personnel, relationships, tools, and procedures. The SLD Spares Assessment Report, dated April 2012, called out the following observations:

Organization. Over the life of the SLD program, the organizational structure has evolved in ways that include changes and realignment of responsibilities among government, partner country, and national laboratory partners. Currently the responsibility for the Sustainability program is consolidated at the NNSA SLD Sustainability Program. Execution of sustainability functions is carried out collaboratively with national laboratories and LMPs in partner countries.

Technology. The current fleet of installed radiation detection equipment represents over a decade of evolutionary improvement in capability and reliability enhancements. Lessons learned from the initial deployments of this equipment have been incorporated into new system and component designs as well as better maintenance and operational procedures. Consequently, the installed fleet is a system of heterogeneous systems.

Policy. With respect to both sustainability and design/build contracting, the implementation of SLD sites, training, management, and maintenance have all evolved over the life of the program in response to feedback, emerging requirements, and a robust lessons learned process along with an information sharing culture.

Procedure. Especially as regards maintenance, training, assurance, and sustainability contracting, the documented procedures and best practices under which actions are carried out have seen continuous evolution and improvement.

Classic supply chain management principles, for example as discussed in Hugos (2003) and Handfield and Nichols (2002) are applicable to SLD Sustainability only insofar as the program can access and use information, enforce the application of standardized procedures, and build competency among all partners with a role in operating a spares system. In addition to these observations, the assessment provided recommendations for improving

1. Information and data management

2. Resource management and materials handling

The spares study has also led to pilot programs for sourcing alternatives that include regional intermediate inventories and partnering agreements that leverage existing manufacturer supply chains.

\subsubsection{Information and Data Management}

Overall, sustainability information, including information about maintenance activities and spares, is collected and distributed in too ad hoc a manner to permit effective centralized visibility of the status of spares throughout the program. Without this visibility, the spares program will be forced to operate in a 
distributed fashion with each sustainability manager responsible for building a standalone system. A systematic approach to spares management can promote more effective enterprise-wide information management.

The assessment report identified next steps related to the information and data environment:

- Enumerate the formal and informal information pathways currently used

- Determine which pathways are of potential use in a formal spares management process

- Catalog the data repositories into which information about maintenance and spares is collected

- Evaluate the contents, periods of coverage, and quality of these data repositories.

The assessment provided an understanding of the existing limitations and constraints that currently prohibit centralized management of all aspects of sustainability. The recommended solutions were designed to permit decentralized execution while providing value to all stakeholders through more complete visibility.

The recommendations resulted in creation of the MPDB and a plan for incorporating that database into the program's data and information management processes.

\subsubsection{Resource Management and Material Handling}

The assessment report identified next steps related to resource management and materials handling:

- Listing the parts that are currently in the spares system via the MPDB

- Associating the parts with an individual maintenance action (repair, replacement, or preventative)

- Classifying parts in terms of maintenance function, cost, recoverability, and special handling considerations

- Identifying the subset of inventory that should be managed formally in a spares program (e.g., controlled spares) via the MPDB.

The comprehensive MPC was generated from available SLD Sustainability program data. This catalog supports materials handling and inventory management by providing the program with a single organized source of information about spares that can be used to build program-wide visibility of inventories. The MPC combines informal unstructured information from maintenance subject matter experts and sustainability managers, with structured and semi-structured data sources. This list will be the basis for an application of conventional supply chain analysis tailored to the unique constraints of the SLD system.

\subsection{Overview of Recommendations}

The analysis phase of the SLD spares study has resulted in the nomination of a uniform set of spares lists built from available data, and applies a consistent set of criteria to categorize the items on these lists in the terms described here. We advocate the development of a living MPC that is periodically modified to reflect ongoing process changes, technology upgrades, and operational needs.

\subsubsection{Spares Data Management}

The MPDB should be placed under configuration management as a single database instance. As the need to manage additional parts is identified, these parts should be added to the database. As parts that are in 
the database become obsolete, this should be reflected in the MPC. Parts should be removed from the catalog when they are no longer required or in inventory, but the database entries for these parts should be maintained.

Changes to the MPDB should be carefully managed. Some changes may be as simple as adding a new item to the catalog list or updating data about an existing part. Structural changes may have deeper consequences. Adding a new field or relationship requires an understanding of the consequences of that change across the program. Therefore, we recommend changes to the catalog be authorized by a single centralized entity responsible for maintenance, modifications, and communication to database users. All users should be able to contribute to the rapid maturation of the data set; however, the execution of changes to data elements should be restricted to a small set of individuals responsible for maintaining the database configuration.

\subsubsection{Integration of Spares Data with Site Configuration Management}

The MPDB provides the ability to designate those spares that are configurable items. Any parts called out specifically as site configuration items should be included in the MPDB and annotated through a flag or field. The MPDB should conform to the definitions in the configuration baseline database to ensure compatibility.

\subsubsection{Spares Inventory Management}

As an extension to this work, we recommend development of an inventory database backed by the MPDB. This would enable consistent program-wide collection of on-hand inventory from each site or LMP. As an initial or trial implementation, the MPC can be filtered by a sustainability manager or LMP to create an extract containing only those parts that are relevant to the particular maintenance activity. The extract can be used to generate an inventory worksheet to be filled out by the LMP. This would create a consistent baseline spare parts inventory for each LMP or spares stocking activity. Based on the recommended stockage levels for those parts (given the characteristics of the site or LMP) the responsible party can decide if additional parts need to be ordered and if so, the quantity of each type. Eventually, inventory management during transition could be automated. This would provide the data quality necessary to enable the spares support processes described in the next section.

\subsubsection{SLD Spares Support Processes}

Spares support processes include reliability analysis and parts sourcing. These processes also support cost and lifecycle analysis. In the near term, reliability, level of repair, and basis of issue analyses require assumptions from manufacturers and rules of thumb. Once an adequate data repository is established, the program can use much higher resolution, more data-aware analyses to support program decision making. We recommend the future integration of formal spares data management with these support processes. 



\section{Recommendations}

During FY 2012, the spares study team conducted an assessment of the SLD spares program, resulting in a set of recommendations for developing processes and tools to improve Sustainability operations during the transition period and to enable site transition. The following sections detail those recommendations, describing the current state and future vision for these processes and products.

\subsection{Spares Data Management}

As part of the spares program assessment, the spares study examined existing data sources, specifically looking at consistency, accuracy, level of detail, and general ease of use and usefulness. Some of the key findings were that the spare parts data were inconsistent between sources and were contained in a variety of locations and formats. The data formats ranged from Excel spreadsheets and PDF documents to appendices in Word documents. Another limitation was that each data source was structured around providing a list of parts for only a specific piece of equipment or equipment product line. The resulting collection of disparate data sources made inquiries and any type of analysis challenging, time intensive, or altogether impossible.

Recommendations for improving spares data and data management revolve around consolidating data, centralizing storage, and enabling efficient analysis and inquiries. A preliminary effort to consolidate the existing data sources is already underway and a first instance of the collection of data resides in a Microsoft Access database, the MPDB. The way forward is to continue to manage a comprehensive parts list as a single, consolidated database, built on the foundation of this preliminary MPDB.

The purpose of the MPDB is to provide a single point of reference for part-specific details. Naming conventions and hierarchical information should also be contained in this database to facilitate inventory management, ordering, analysis, and reporting processes. By having all data stored in a single location, data users will not need to independently conduct a data search and consolidation effort across multiple sources for each management or analysis task.

The MPDB should also be stored as a single instance in a centralized, controlled location, ideally on the same electronic framework as existing program tools like the SLD Portal. This configuration control will ensure the integrity and accuracy of the data, greatly reducing the current problem of having inconsistent data between data sources. An example of this would be in the naming conventions for parts, where the same part may have multiple names in multiple documents, reports, or lists. The combination of a single consolidated data source stored in a centralized, controlled environment enables data users to more efficiently query data and produce reports with better information quality.

The MPDB should be managed by a configuration board or similar single source of authority to ensure proposed or required changes to database structure are coordinated with the processes that use the data. Updates to data should also be carefully controlled to avoid duplicate or erroneous data elements. In the near term, all SLD personnel should be encouraged to identify errors, duplicates, or missing data. This will rapidly mature the database and improve data quality.

A key function of the MPDB is to provide the underlying parts information to populate the MPC and other supporting databases. The MPC is intended as a standalone document and should be the primary means of distributing parts data to the LMP, sustainability manager, and parts ordering entity. A version of the MPC exists as a series of reports generated from the database that pulls part information from the MPDB. Currently the MPDB is implemented in Microsoft Access; however, a straightforward transition 
path to a SQL Server instance is under development for integration with SLD Portal. Views of the MPC are configurable and should support the needs of multiple parts data using entities including LMPs and sustainability managers and analysts.

The MPC is sortable at multiple grouping levels, including by manufacturer, specific end item, configurable item, and nomenclature. These different organization schemes are designed to provide the catalog user with various cross-indexed methods of finding needed parts information. Additional sorting and catalog view groupings can be created as new uses for the data are discovered.

The MPDB and MPC are integral to subsequent recommendations and play a central role in most information sharing processes.

\subsection{Integration with Configuration Management Task Force}

The Configuration Management Task Force is currently collecting and organizing baseline program wide site configuration information. Data concerning the equipment installed at each site will be collected and consolidated into a single authoritative data source for baseline configurations.

As the configuration database matures, design adjustments to the MPDB should be implemented to maintain alignment between the two databases. Those items (and/or parts) designated as configuration items can be annotated in the MPDB records. This provides additional reporting and catalog generation abilities. For example, a catalog extract containing only configuration items can be generated with a simple filter. Designating configuration items in the MPDB will permit linking individual cataloged parts to the unique configurable items. The configuration baseline is not collecting spares inventory data, only components that are part of the operational installed set. An excerpt from the Malta, Port of Marsaxlokk configuration baseline worksheet is shown in Figure 2.1.

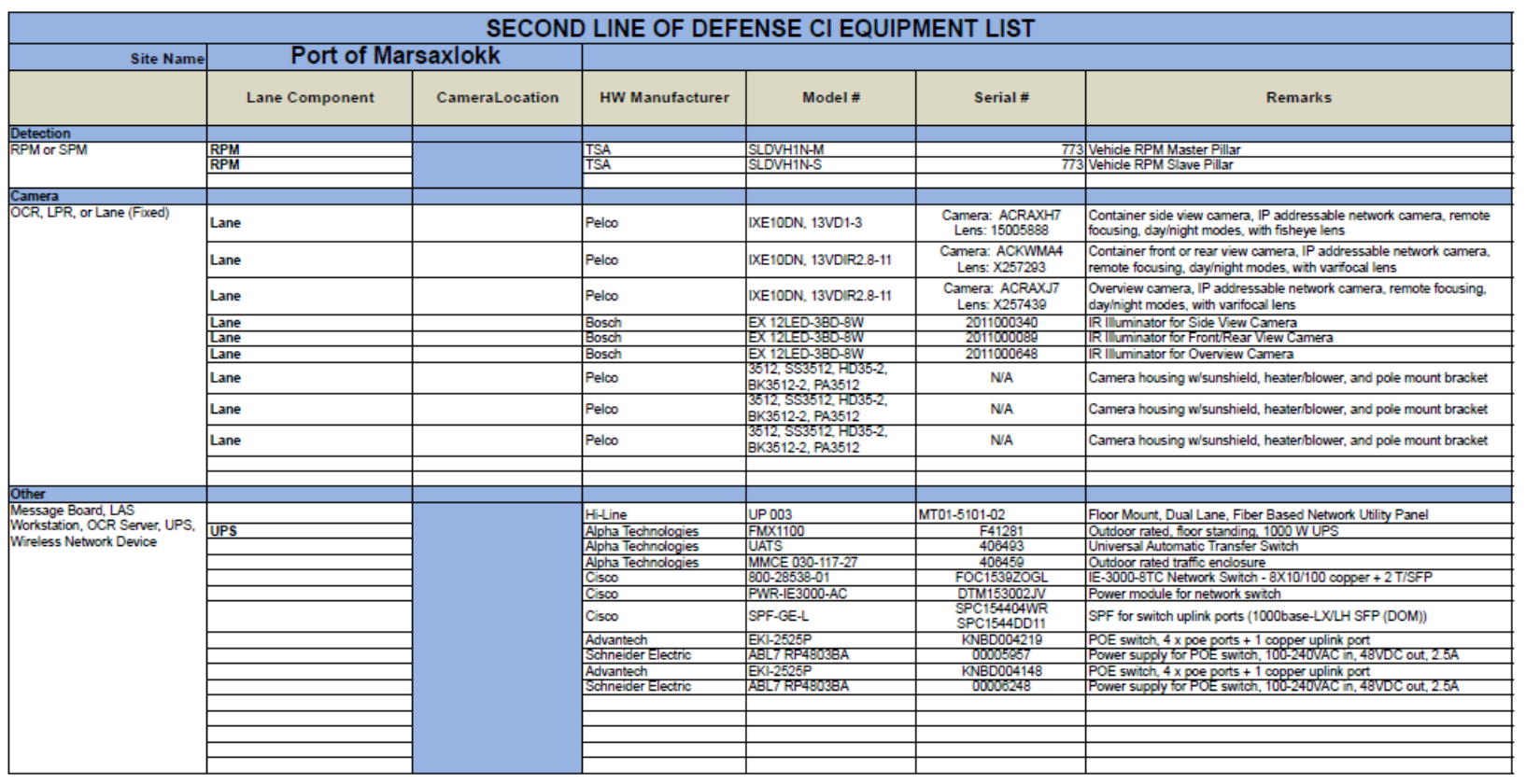

Figure 2.1. Example Configuration Baseline Data

Figure 2.1 shows a single tab containing information about one of the lanes at the site. The information is organized by system function and includes manufacturer, model, model number, and serial number 
details. The MPC does not track parts at the serial number level of detail, and the configuration baseline does not currently provide spare parts in inventory (only components that are in operational use).

\subsection{Inventory Management}

The MPC and MPDB can be used to obtain much more accurate inventory visibility across the program. Current inventory management practice is not standardized across the program. Sustainability managers and LMPs meet contractual obligations to maintain and report inventories, but they do not provide those inventories in a form that can be readily consolidated to support program-level decisions or analysis.

Inventories by LMPs of the spares available at sites or in intermediate storage facilities should be taken and maintained against the standard part designations of the MPC. The relationship between a comprehensive catalog and an inventory management program is shown in Figure 2.2.

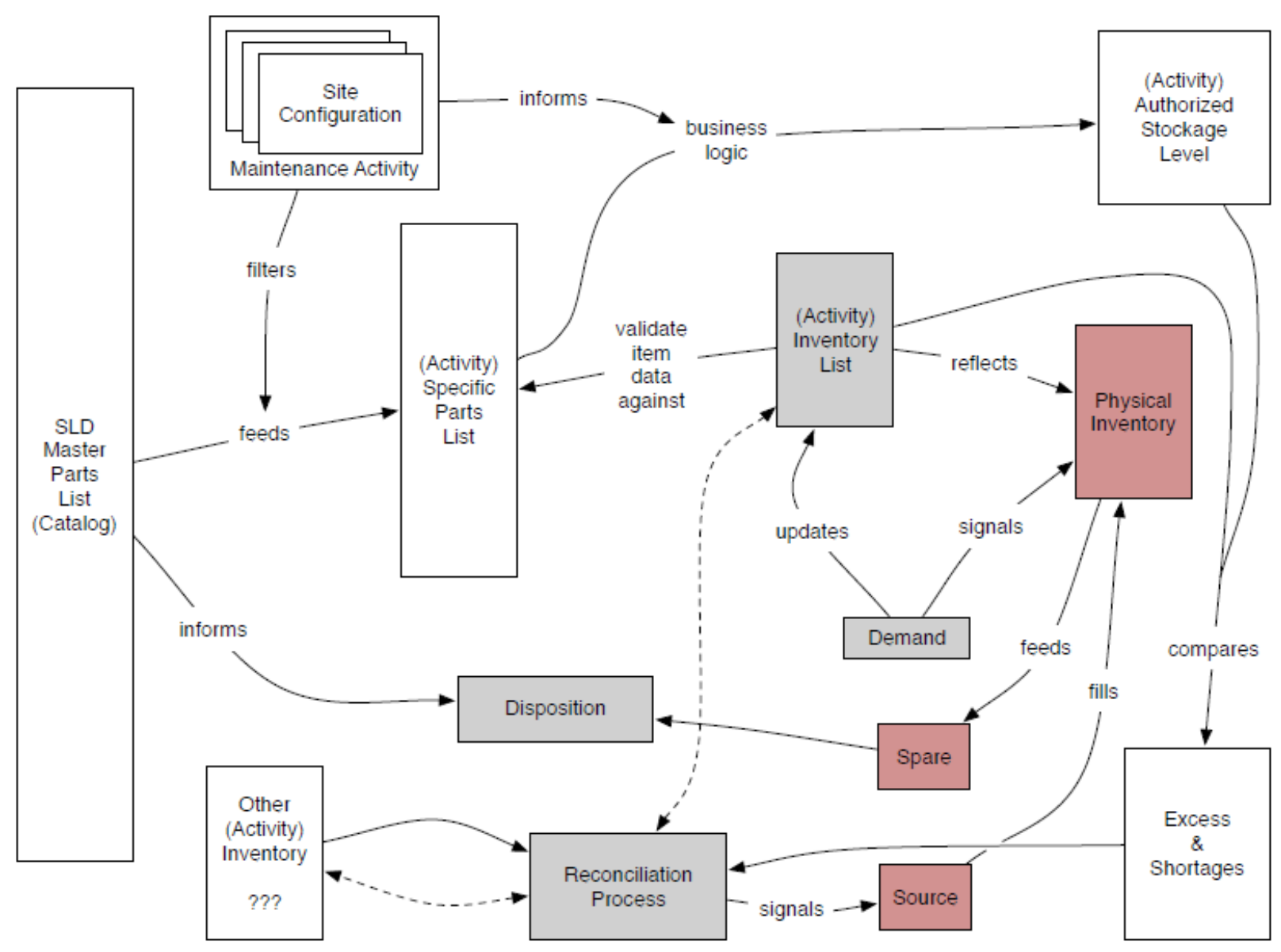

Figure 2.2. Catalog and Inventory Process Relationships

The MPC can be used to generate a catalog extract specific to a site's configuration or fleet of deployed equipment in an LMP's scope and the supporting maintenance activity. In conjunction with business logic, the extract can inform an authorized (or recommended) stockage level for spare parts. It can also provide an inventory listing or inventory collection worksheet. 
Inventories collected either offline through worksheets or through integration with the SLD Portal would provide the program a more complete visibility of inventories and usage. This would support decisions about reconciling overages and shortages. It would also enable clear program guidance about difficult-tosource or expensive parts, recovery of parts for failure analysis, correct disposition of parts, and upgrades or refreshes to the system that might require recovery or restocking parts in the deployed inventory.

\subsubsection{Site-Specific Catalog Extracts}

Site-specific catalog extracts can be generated from the MPDB if information about the site (or LMP) equipment fleet is available. A design goal for the integration of parts, configuration, and inventory data is to produce catalog extracts dependent on site configuration of equipment and informed by current inventory levels. Site-specific extracts will also limit errors in recording and ordering parts. Inventories collected against the catalog standard will provide a much clearer picture of the state of inventory, including obsolete (e.g., non-potted) parts in inventory, not just in operational use. Program execution will remain decentralized. This means that inventory visibility will never be real-time. However, even under quarterly or longer inventory update periods, program managers and analysts will have a more agile process for organizing data and making estimates to support decisions and communication.

Ideally, collected configuration data would be linked to the MPDB and catalog extracts would be created automatically by selecting the site of interest. The extracts would be populated with required parts for the specific equipment at the site as called out in the configuration baseline. In the absence of configuration data for sites, the MPC should include form functionality that allows a user to select equipment from a list to generate the catalog extract with only parts required to support the customized selection.

\subsubsection{Stockage Levels}

Recommended or authorized stockage levels specific to a site or LMP can be generated using the database tool. The existing basis of issue information in the database is of uncertain value. However, future spares management actions could enable a more robust spares inventory estimating process informed by consistently collected data. Given credible failure estimates and stockage level recommendations paired with accurate inventories, the program could have visibility of potential parts for order

1. Shortages

2. Excess

3. Program-wide spares issues

4. Site-specific, unique, or isolated issues

As currently designed, each part has a designated "basis of stockage" and a corresponding "stockage quantity.” For example, consider an LMP that maintains three sites, $(A, B, C)$. Assume that these sites are each configured with a particular portal monitor in quantities of six, 14 , and eight, respectively. The LMP then has maintenance responsibility and should stock spares to support 28 systems. Each of the parts associated with this particular end item has a basis of stockage and stockage quantity. For a specific part, assume that the basis of stockage is per 10 systems and the stockage quantity is designated as four. Then the recommended stockage level (RSL) for this LMP would be:

$$
\begin{aligned}
\text { RSL } & =\text { number of systems } \times \text { stockage quantity } \div \text { basis of stockage } \\
& =28 \times 4 \div 10 \\
& =11.2
\end{aligned}
$$


The RSL would be either 11 or 12 spares. A different part might have a basis of stockage of per site, with a stockage quantity of two. For this part, the RSL for this LMP would be:

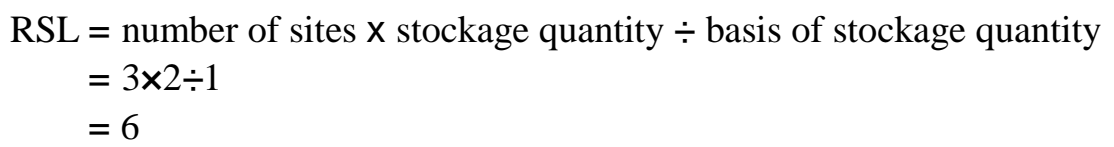

Business logic would need to handle rounding and exceptions, for example imposing adjustments to RSL for expensive, difficult to source, or controlled items.

\subsubsection{LMP Reporting}

The SLD Portal should adopt the MPDB and underlying functions to enable accurate inventory reporting and enforce the correct, consistent attribution of a failure incident to a specific identifiable spare part. Accurate identification and communication of part details are critical to avoiding unnecessary time and money spent on identifying and procuring the correct part. Currently the Portal permits free text insertion of parts information associated with a failure or maintenance action. This presents challenges to analysts and managers when they require correlated information about spares and maintenance activities. The MPDB can be used to populate pulldown menus in the Portal reporting system so that spares data is consistently gathered and readily available for future analytic needs.

\subsubsection{Inventory Reconciliation}

More accurate inventory visibility will permit a tailorable reconciliation process during transition under which excess and obsolescent parts could be identified, retrieved, retrofitted, replaced, and cross-leveled. A reconciliation process for excess and shortage would incorporate information about LMPs, regions, countries, agreements, and contracts. In many cases, no direct reconciliation action would be feasible or desired; however, inventory visibility would permit better execution of decisions to buy forward or refresh parts in existing inventories. The MPDB, MPC, and inventory program should be used to instantiate policies where program assets are distributed in the most effective way possible given host country, site, and LMP constraints.

\subsection{SLD Spares Support Processes}

Supporting processes include analysis, budgeting, and decision support activities that would be more agile, accurate, or efficiently implemented under the data and material management programs provided in the previous sections.

\subsubsection{Reliability Analysis}

Better information would enable reliability analysis, which is briefly described here. The development of a parts database, combined with inventory and site configuration information, provides a baseline for more technically complete reliability analysis that would be useful for a variety of purposes. In the context of spare parts processes, a critical gap is the ability to understand and make estimates on the expected life, remaining life, and lifecycle costs of equipment and components. Collection of basic information, such as failures, types of failures, age of equipment, or failures attributable to specific parts can inform a reliability analysis. These are currently built from labor intensive analysis of records that are not collected or stored with this purpose in mind. 
Failure analysis is conducted as a forensic engineering study of failed components and is fed by anecdotal or obvious design shortcomings rather than in a data-informed way. Reliability analysis can provide a better basis for stocking levels for critical or key spare parts than the existing manufacturer estimates. In addition, better data about faults and failures attributable to parts could inform routine and preventive maintenance actions and condition-based replacement.

Reliability analysis does not need to be performed for every part in the database. Parts should be identified for analysis based on several key factors, including cost, limit of availability (long-lead times, sourcing challenges), criticality to site function, and high failure rates or obvious age driven failures. The underlying principle is to maintain adequate system operational readiness, ensuring that identifiable reliability issues do not create a situation where system function is compromised. There are a variety of methods for modeling reliability and the application is dependent on the nature of the part, equipment, or system being analyzed. Some of the most commonly used techniques include failure rate analysis (Mean Time to Failure), Weibull product life modeling, and fault tree diagrams.

Collection of data and analysis of observed failures is a critical element to performing reliability analysis, but also important is the design and inclusion of reliability testing methods to identify trends that may lead to system failure. System-up time can often be increased by developing effective testing methods to identify reliability issues before a failure occurs.

\subsubsection{Spares Sourcing}

Because many sources are available for some parts, and the source of a part can vary over time and between country, site, and LMP, spares sourcing information should be collated outside of the MPC and included in supporting views of the database. The team has collected some spares sourcing data, but the nature of sourcing information is such that continual updates are necessary as changes in sources are made. A prototype catalog view that provides a substantially complete list of sources linked to specific manufacturers is being developed as part of the database.

The attribution of a particular set of sources to a particular LMP or spares stocking activity would require additional effort. Similarly, providing resolution of the specific parts from a particular manufacturer that can be obtained from a particular source would require additional effort. 


\section{Spares Catalog Implementation}

A significant outcome of the SLD spares study is the accumulation and collation of many sources of spare parts data into a formal database implementation. The database exists as an initial nominated standard. Specific recommendations for future use are called out in Section 2. This section describes the existing database implementation and standards for managing parts information as data and disseminating parts data in the form of catalog views. In addition to providing a single configuration controlled source for spare parts data, the database and catalog views can be used to support other program functions, for example inventory management.

This database catalogs information about every part, set, kit, tool, or component in the program as a catalog item; it does not account for every unique instance of each part that exists in inventory. An inventory management system could be built by integrating information from this catalog and the configuration items database.

\subsection{Master Parts Database}

The MPC is backed by the MPDB implemented in Microsoft Access. The database provides the SLD Sustainability program a method of maintaining a single authoritative list of parts and consistent data attribute management via a relational design. The database also includes convenience data management forms and report generating functions. A schematic view of the database design is shown in the relationship diagram marked Figure 3.1. Specific definitions and descriptions of managed data elements are provided in Section 3.3

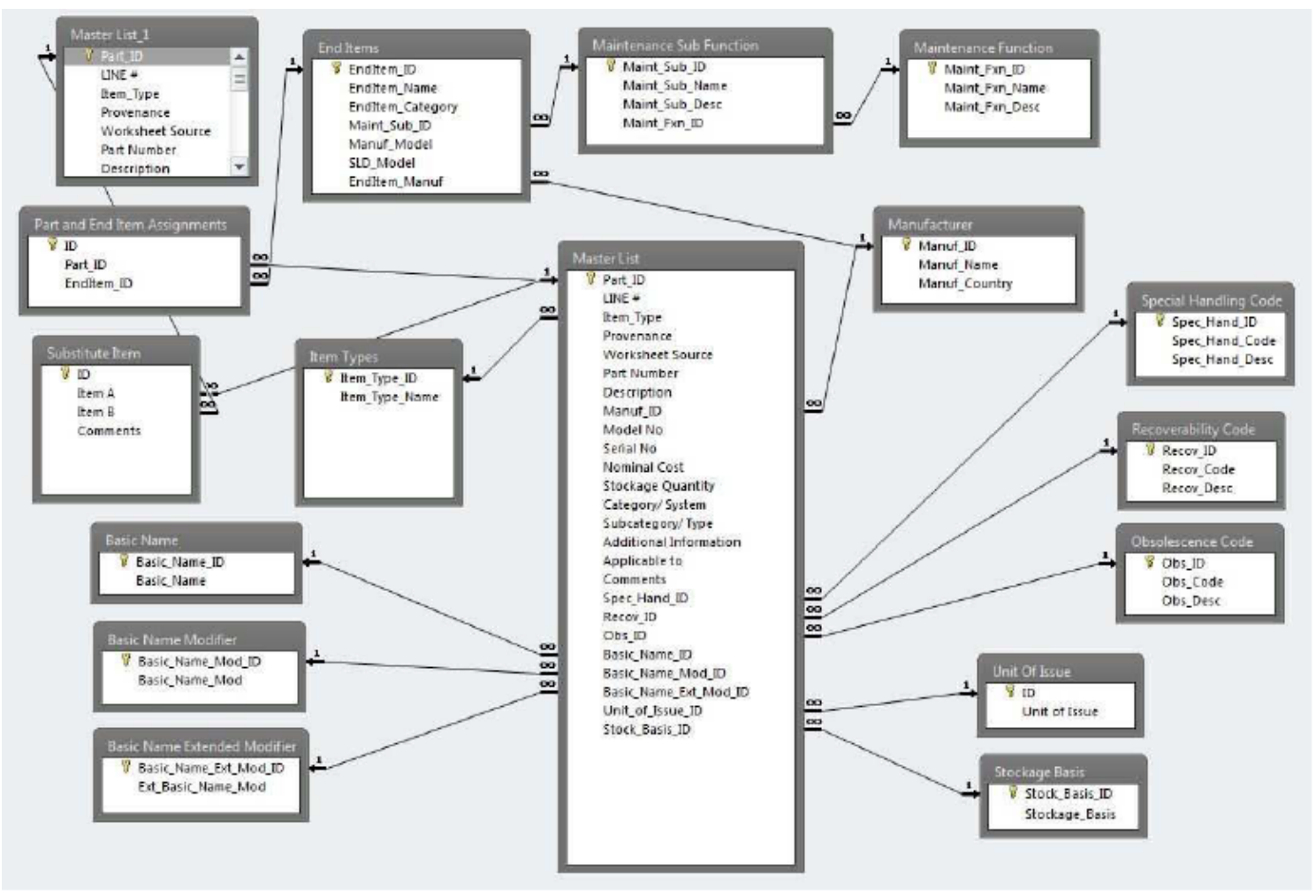

Figure 3.1. MPDB Relational Table Diagram 


\subsection{State and Provenance of Data Sources}

The data sources used to create the current database include:

1. Data that has been collected into Excel spreadsheets for various uses

2. Manufacturer's parts lists in various electronic plain text formats

3. Paper copies of parts lists and catalogs

The specific data source and provenance of each part are preserved in the database. An extract of the unique elements of provenance from the database are shown in Table 3.1.

Table 3.1. Provenance Elements in Database

\begin{tabular}{|c|c|}
\hline Provenance & Worksheet Source \\
\hline Aspect Spare Parts Calculator v2.xlsx & Calculation \\
\hline Aspect Spare Parts Calculator v2.xlsx & Telecommunications \\
\hline Aspect Spare Parts Calculator v2.xlsx & Video Monitoring \& Server \\
\hline $\begin{array}{l}\text { Data Acquisition, processing and displaying system. Composition Catalog } \\
\text { Rev.1 }\end{array}$ & Table B.6 \\
\hline Initial Sihanoukville Spare Parts Inventory & Traffic Arms \\
\hline Malaysia, Port Klang Spare Parts List Siemens & OCR \\
\hline Multiple sources & Table B.4 \\
\hline $\begin{array}{l}\text { Spare Parts Recommendations based on Aug-2011 v.2, Make Model } \\
\text { Recommended Spare Purchase file }\end{array}$ & APS OCR \\
\hline $\begin{array}{l}\text { Spare Parts Recommendations based on Aug-2011 v.2, Make Model } \\
\text { Recommended Spare Purchase file }\end{array}$ & HTS OCR \\
\hline $\begin{array}{l}\text { Spare Parts Recommendations based on Aug-2011 v.2, Make Model } \\
\text { Recommended Spare Purchase file }\end{array}$ & SAFEPASS CAS \\
\hline $\begin{array}{l}\text { Spare Parts Recommendations based on Aug-2011 v.2, Make Model } \\
\text { Recommended Spare Purchase file }\end{array}$ & Schneider CAS \\
\hline $\begin{array}{l}\text { Spare Parts Recommendations based on Aug-2011 v.2, Make Model } \\
\text { Recommended Spare Purchase file }\end{array}$ & Serco CAS - 1 Generation Old \\
\hline $\begin{array}{l}\text { Spare Parts Recommendations based on Aug-2011 v.2, Make Model } \\
\text { Recommended Spare Purchase file }\end{array}$ & Serco CAS - 2 Generations Old \\
\hline $\begin{array}{l}\text { Spare Parts Recommendations based on Aug-2011 v.2, Make Model } \\
\text { Recommended Spare Purchase file }\end{array}$ & Serco CAS - 3 Generations Old \\
\hline $\begin{array}{l}\text { Spare Parts Recommendations based on Aug-2011 v.2, Make Model } \\
\text { Recommended Spare Purchase file }\end{array}$ & Serco CAS - Current \\
\hline $\begin{array}{l}\text { Spare Parts Recommendations based on Aug-2011 v.2, Make Model } \\
\text { Recommended Spare Purchase file, Port Klang, Malaysia }\end{array}$ & Siemens Wireless Network \\
\hline $\begin{array}{l}\text { Spare Parts Recommendations based on Aug-2011 v.2, Make Model } \\
\text { Recommended Spare Purchase file, Port Klang, Malaysia. }\end{array}$ & Serco Wireless Network \\
\hline $\begin{array}{l}\text { Spare Parts Recommendations based on Honduras Spares Inventory 4/16/07 \& } \\
\text { Port of Manzanillo (MX), 12/19/08 }\end{array}$ & ICIS OCR \\
\hline $\begin{array}{l}\text { Spare Parts Recommendations based on Latvia example \& Aug-2011 v.2, Make } \\
\text { Model Recommended Spare Purchase file, Raven Spare Price List }\end{array}$ & RAVEN CAS \\
\hline $\begin{array}{l}\text { Spare Parts Recommendations based on Latvia example \& Draft Typical CORE } \\
\text { Site Spares List (4/28/10); Port of Kaohsiung, Taiwan, Spares Inventory; Port } \\
\text { Klang, Malaysia }\end{array}$ & Utility Panels \\
\hline
\end{tabular}




\begin{tabular}{ll}
\multicolumn{1}{c}{ Provenance } & \multicolumn{1}{c}{ Worksheet Source } \\
\hline $\begin{array}{l}\text { Spare Parts Recommendations based on manufacturer spare parts list 2008, SLD } \\
\text { Help Desk/Spare Parts/Thermo Spares List 2012, with PNNL preferred pricing } \\
\text { good through 12-31-12 }\end{array}$ & \\
Spare Parts Recommendations based on TSA 2011 recommendations & TSA \\
TSA SparePartsPictorial11-10.pdf & TSA \\
Video monitoring system. Composition Catalog Rev.1 & Table B.6 \\
\hline
\end{tabular}

\subsection{Definitions and Descriptions}

The data elements defined in this chapter are an initial nominated specification for fields within catalog records.

\subsubsection{Nomenclature}

The nomenclature field is a regularized basic name that follows a general to specific, comma separated pattern of at least one and up to three levels:

Basic name. The fundamental function or most general useful name for an item, e.g., CABLE

Basic name modifier. A modifier to the basic name that makes the function or description more complete, a type, e.g., USB

Basic name extended modifier. An extension that distinguishes the item from similar items or makes its purpose clear, e.g., 6 FT

The nomenclature field is backed by three tables in the MPDB. These tables are used to construct the nomenclature from regularized components, e.g., CABLE, USB, 6FT. Nomenclature is spelled out entirely in capital letters.

\subsubsection{Unit of Issue}

Unit of issue (UI) is the count of the item that is provided by the catalog entry. Most items have basis of issue $E A$, meaning each, which denotes a single item. The current UI codes are defined in Table 3.2.

Table 3.2. Unit of Issue Codes

\begin{tabular}{ll}
\hline \multicolumn{1}{r}{ Code } & \multicolumn{1}{c}{ Explanation } \\
\hline EA & each \\
KIT & kit \\
SET & set \\
HND & hundred count \\
GRS & gross \\
DOZ & twelve count \\
GAL & US gallon \\
4 PCS & 4 pieces \\
12 PCS & 12 pieces \\
16 PCS & 16 pieces \\
24 PCS & 24 pieces \\
\hline
\end{tabular}




\subsubsection{Cost}

Cost data are maintained in current fiscal year U.S. dollars. The quality of the existing cost data vary widely depending on the source for the catalog item. Cost data are presented in this version for staffing and rough estimates only. Ultimately, cost data should reflect an authoritative planning figure, but the contract cost to deliver a particular part to a particular point of need may vary substantially from the figure in the database. Depending on the situation, it may be useful to store site or LMP specific costs for spare parts in a separate database linked to inventory at that site or LMP.

\subsubsection{Basis of Stockage Level}

The basis of stockage level is the basis against which a stockage level for the part should be calculated. The basis of stockage level is paired with a quantity against which to apply the basis. For example, a part that has a basis of per 10 systems and a quantity of two should be stocked in a quantity of two per 10 systems supported by the stocking maintenance activity. The basis of stockage level and quantity data are intended for use in a business logic that accounts for rounding, minimums, and restrictions on stockage. The existing values for basis of issue are defined in Table 3.3.

Table 3.3. Basis of Stockage Level Codes

\begin{tabular}{ll}
\hline \multicolumn{1}{c}{ Code } & \multicolumn{1}{c}{ Explanation } \\
\hline 10 Systems & The basis of issue is quantity per 10 supported end item systems \\
10 CAS & The basis of issue is quantity per 10 supported CAS systems \\
Site & The basis of issue is quantity per supported site \\
None & No basis of issue, do not stock this as a spare against a basis of issue \\
10 OCR & The basis of issue is quantity per 10 supported OCR Systems \\
10 Traffic Arms & The basis of issue is quantity per 10 supported traffic arms \\
Each & The basis of issue is quantity per end item supported \\
1 System & The basis of issue is quantity per 1 supported end item system \\
\hline
\end{tabular}

\subsubsection{Recoverability Code}

The recoverability code provides guidance on the disposition of a failed part and the level at which parts may be disposed, determined to be economically repairable, and repaired for return to inventory. The recoverability codes are defined in Table 3.4.

Table 3.4. Recoverability Codes

\begin{tabular}{cl}
\hline Code & \multicolumn{1}{c}{ Explanation } \\
\hline Z & $\begin{array}{l}\text { Non-recoverable; dispose of at LMP/Operator level when } \\
\text { unserviceable } \\
\text { Recoverable; at manufacturer level } \\
\text { I }\end{array}$ \\
O & Recoverable; at intermediate level \\
X & No recoverability guidance for this part \\
\hline
\end{tabular}




\subsubsection{Special Handling Code}

Special handing codes provide guidance for parts that require special handling or are currently being recovered under special circumstances, for example for failure analysis. The special handling codes are defined in Table 3.5.

Table 3.5. Special Handling Codes

\begin{tabular}{cl}
\hline Code & \multicolumn{1}{c}{ Explanation } \\
\hline M & Item is high value or contains high value components \\
H & Item contains hazardous material \\
F & Item should be recovered under special instruction for failure analysis \\
MH & High value and hazardous material \\
MF & High value and failure analysis required \\
HF & Hazardous material and failure analysis required \\
MHF & High value, hazardous material, and failure analysis required \\
X & No special handling required \\
\hline
\end{tabular}

\subsubsection{Obsolescence Code}

The obsolescence code is intended as a way to call out parts that are nearing end of life and will become difficult to source. It can also be used for parts that may remain in service, but that have become obsolete and will be replaced by a different part or through a system upgrade. A special case of obsolescence coding is the distinction between potted and non-potted versions of high-voltage detector components. Both versions exist in inventory and the version can be distinguished by manufacturer's part number. As the retrofit to potted parts is completed, these codes may no longer be needed. The obsolescence codes are defined in Table 3.6.

Table 3.6. Obsolescence Codes

\begin{tabular}{cll}
\hline Code & \multicolumn{1}{c}{ Explanation } \\
\hline $\mathrm{X}$ & No obsolescence information available \\
$\mathrm{A}$ & Active \\
$\mathrm{O}$ & Obsolete \\
$\mathrm{E}$ & Nearing end of life \\
$\mathrm{P}$ & Potted version \\
$\mathrm{NP}$ & Non potted version \\
\hline
\end{tabular}

\subsection{Database Management}

\subsubsection{Update and Ingestion Process}

The initial ingestion of a large amount of spares data is complete. As additional data sets or unstructured lists are found, or as missing parts information is discovered, these gaps should be reconciled by an ingestion process. These ingestions will be necessarily ad hoc and depend on the nature of the discovered spares information; however, the database is substantively complete at this time. 
A more important workflow going forward is update and correction of data that are missing or in error. These operations can be carried out directly in the database tables or through several convenience forms that have been developed. These forms should not be exposed to a large number of users. The ingestion, cleaning, and completing of data should be carried out under the control of a single owner of a single managed instance of the database.

\subsubsection{Structure, Relationships, and Modification Process}

Changes to the underlying structure or relational tables in the database should by undertaken only with a clear knowledge of the impact of these changes on other elements of the SLD Sustainability program. There are only a few necessary types of manipulation.

Ingestion. Ingestion of significant new record sets (e.g., more than a few distinct new and unique items) should be accomplished by a database developer.

Changes to codes and definitions. As the catalog is adopted and the database used to provision more functions, managers and operators in the program may identify the need for additional codes or data elements. These changes should be vetted and then implemented by a database developer.

Error correction and filling in blank data. It would be useful to provide forms for making small changes to individual records to people across several SLD Sustainability roles. People in Help Desk, maintenance, and spares management roles will encounter small errors in the data that they should be empowered to correct without the requirements of a major configuration change. Their input will more rapidly clean the existing record.

\subsubsection{Configuration Management}

A spares database configuration board should be empaneled and given the authority to accept and implement changes to the structure of the database, catalog views, and integration with other program databases. The database should be managed as with enterprise data best practices and a single, versioned, authoritative instance should be used for spare parts functions program wide.

\subsection{Master Parts Catalog}

The MPC is intended as a comprehensive listing of repair parts, components, kits, and consumable items used on the equipment deployed at SLD sites worldwide. The catalog covers detection, central alarm station, network, and ancillary equipment. The catalog is backed by the MPDB, which is used to generate the report views of the catalog. The MPDB is a relational database containing a record for every part in the MPC along with supporting tables for normalizing fields in the records. The MPDB also includes supporting queries and standard reports, including those reports used to build the catalog.

\subsubsection{Purpose and Use}

The MPDB serves several purposes in the context of the SLD Sustainability program as shown in Figure 3.2. The MPDB is a component of the SLD Portal, which may also mirror the structured configuration baseline database. The MPDB conforms to the standards in the configuration database, and will call out individual parts that are also configuration items. The MPDB is used to generate the MPC. This catalog serves as an authoritative way to unambiguously identify parts under inventory management and will provide the underlying structure for a future inventory management system. 


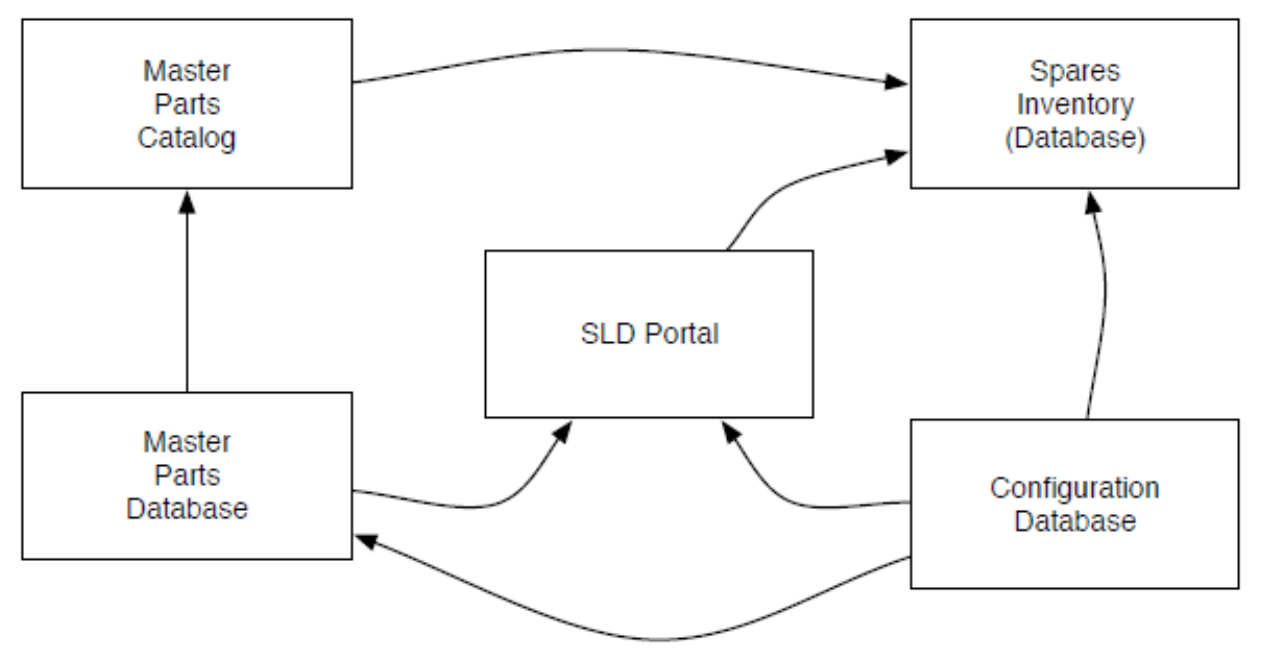

Figure 3.2. MPC Context

\subsubsection{Catalog Views}

The MPC consists of the following views of the MPDB.

Nomenclature view. A list of every part in the catalog sorted alphabetically by standard name or nomenclature.

Manufacturer view. A similar list grouped by the part manufacturer.

End item view. Grouped by the major piece of equipment to which the part applies.

Requirements are under review for additional views either as part of the catalog or as adjuncts or supporting catalog documents. These include:

Tools and test equipment view. The database filtered so that only catalog items that are tools are presented.

Sourcing view. An extension of the database is under development that can provide a view of all of the known or authorized sources of parts organized by their manufacturer.

Configuration items view. The database filtered so that only parts that are under configuration management are presented. 



\section{Recommendations for Near-Term Implementation}

This section provides an immediate way that the SLD Sustainability program could exploit the work done in the spares analysis with several discrete efforts achievable during fiscal year 2013.

\subsection{Integrate Master Parts Database with Portal}

The MPDB is mature enough that it could be pulled into the SLD Portal with relatively low effort. Once integrated, MPC data could be used to populate dropdowns in the trouble-reporting system used by LMPs so that discrete parts could be linked to identified system faults. This will identify gaps in the catalog as the LMPs annotate faults for which the component or part does not exist in the database. Exposing the data in its existing state would rapidly mature data quality. The integration should include convenience and development forms and report generation functions for use by data managers, but this would not be exposed to all Portal users.

\subsection{Integrate MPC with Site Configurable Items Database}

As the Configuration Task Force compiles the baseline data and instantiates a configuration items baseline database, any necessary refactoring of the MPDB should be completed. Compatibility between the databases will permit Portal functions and views that move the MPDB beyond catalog and inventory support tools into a full inventory management and visibility system as described in Krajewski et al. (2007).

\subsection{Data-Driven Reliability Analysis}

The information generated by a period of consistent use of these data capture tools will greatly enhance transition by providing partner countries with realistic, data-driven reliability estimates and stockage recommendations. 



\section{References}

Handfield R and E Nichols. 2002. Supply Chain Redesign. Prentice Hall, New Jersey.

Hugos M. 2003. Essentials of Supply Chain Management. John Wiley and Sons, New Jersey.

Krajewski L, L Ritzman, and M Malotra. 2007. Operations Management Processes and Value Chains. Prentice Hall, New Jersey. 


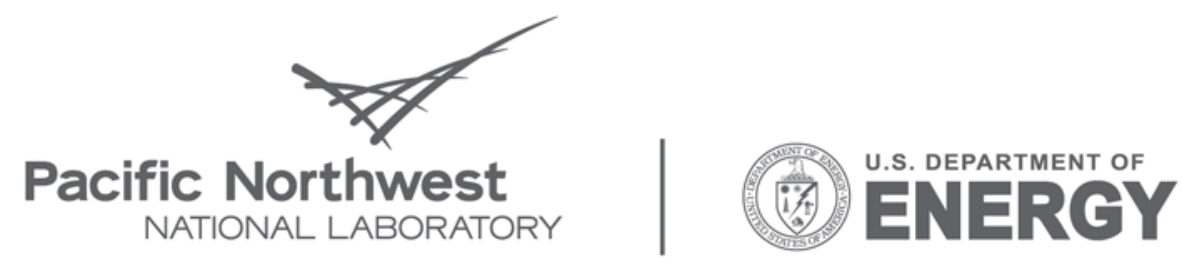

Proudly Operated by Battelle Since 1965

902 Battelle Boulevard

P.O. Box 999

Richland, WA 99352

1-888-375-PNNL (7665)

www.pnl.gov 